\title{
Avaliação histopatológica da cápsula posterior associada ao implante de lente intraocular com superfície modificada com plasma de flúor e polietilenoglicol em coelhos
}

\author{
[Histopathological evaluation of posterior capsule associated with intraocular lens implant with \\ modified surface using fluorine and poliethilene glycol plasma in rabbits] \\ V.L. Souza ${ }^{1}$, C.H. Pellizzon ${ }^{2}$, M.G. Sereno ${ }^{3}$, R.T. Soares ${ }^{4}$, J.J.T. Ranzani ${ }^{3}$, A.C.L. Rodrigues ${ }^{5}$, \\ C.R. Padovani ${ }^{2}$, C.V.S. Brandão ${ }^{3}$ \\ ${ }^{1}$ Aluno de pós-graduação - FMVZ - UNESP - Botucatu, SP \\ ${ }^{2}$ Instituto de Biociências - UNESP - Botucatu, SP \\ ${ }^{3}$ FMVZ - UNESP - Botucatu, SP \\ ${ }^{4}$ UNESP - Sorocaba, SP \\ ${ }^{5}$ FM - UNESP - Botucatu, SP
}

\begin{abstract}
RESUMO
O objetivo deste estudo foi avaliar o efeito do tratamento da superfície de lentes intraoculares acrílicas utilizando-se plasma de flúor ou polietilenoglicol na prevenção da opacidade de cápsula posterior. Foram analisados 40 olhos de coelhos, submetidos à cirurgia de facoemulsificação e distribuídos em quatro grupos experimentais $(\mathrm{n}=10)$, sendo estes: grupo controle, coelhos sem implante de lente intraocular; grupo com lente intraocular tratada com plasma de polietilenoglicol; grupo com lente intraocular tratada com plasma de flúor; e grupo com lente intraocular comercial. As cápsulas posteriores das lentes dos grupos foram avaliadas por meio de análise histopatológica (morfometria e imuno-histoquímica). Os grupos com lente intraocular tratada com polietilenoglicol e com lente intraocular comercial apresentaram menor espessura da cápsula posterior na avaliação inicial (12 semanas) em relação ao grupo controle. No período final de avaliação (6 meses), os tratamentos da superfície da lente intraocular à base de plasma de flúor e polietilenoglicol não reduziram o desenvolvimento das alterações histológicas associadas à opacidade de cápsula posterior. O tratamento das superfícies das lentes intraoculares com plasma de flúor e polietilenoglicol pode ser realizado como adjuvante na prevenção da opacidade de cápsula posterior, pois não causa alterações na morfologia da lente após facoemulsificação.
\end{abstract}

Palavras-chave: coelho, opacidade, capsular, morfometria, imuno-histoquímica

\begin{abstract}
The aim of this study was to evaluate the effect of surface treatment of acrylic intraocular lens using Fluorine plasma or polyethylene glycol in the prevention of posterior capsule opacification. Forty rabbit eyes that underwent phacoemulsification were analyzed and distributed into four experimental groups $(n=10)$ : Control group, composed of rabbits without intraocular lens implantation; intraocular lens group treated with Polyethylene glycol plasma, intraocular lens group treated with Fluoride plasma, and commercial intraocular lens group. The posterior capsule of the lens was evaluated by histopathological analysis, including morphometric and immunohistochemical studies. Groups with intraocular lens treated with polyethylene glycol and commercial intraocular lens presented thinner posterior capsule at initial assessment (12 weeks) compared to the control group. At the end of the evaluation (six months), the treatment of surface intraocular lens with fluorine and polyethylene glycol plasma did not reduce the development of histological changes associated with posterior capsule opacification. The surface treatment of the intraocular lens with Fluoride and Polyethylene glycol can be performed as an adjuvant in preventing posterior capsule opacification, because it does not cause changes in the morphology of lens after phacoemulsification surgery.
\end{abstract}

Keywords: rabbit, opacification, capsular, morphometry, immunohistochemistry

Recebido em 10 de setembro de 2014

Aceito em 11 de junho de 2015

E-mail: valeriasb@fmvz.unesp.br 


\section{INTRODUÇÃo}

A opacidade de cápsula posterior (OCP), denominada também como catarata secundária, é a complicação mais comum após a remoção cirúrgica da catarata. No decorrer da sua evolução, verificam-se crescimento, proliferação, migração e transformação das células do epitélio da lente (CEL) presentes na cápsula anterior remanescente, sob a cápsula posterior inicialmente livre de células (Raj et al., 2009; Wormstone, 2009). O tratamento da LIO utilizando-se o processo de plasma, independentemente do plasma utilizado, promove a "ativação" da superfície, ou seja, a incorporação de grupos polares que modificariam suas características superficiais (efeito na adesão ou repelência celular e proteica) (Coltro e Alves, 2001; Kim et al., 2001).

A repelência celular e proteica do polietilenoglicol (PEG), decorrente de suas propriedades atóxica, não imunogênica e não antigênica, seleciona-o como substância adequada a ser aplicada nas superfícies dos materiais para a confecção de Lios (KIM et al., 2001; Bozukova et al., 2007; Sereno, 2012). A utilização de grupos fluorados, como hexafluoreto de enxofre ou tetrafluorocarbono, é capaz de conferir alta hidrofobicidade às superfícies, favorecendo a biointegração dos materiais biológicos (Werner et al., 1999).

As considerações descritas acima, associadas à alta morbidade da OCP na Medicina Veterinária (Davidson et al., 2000), bem como os escassos estudos relacionados à mesma, especialmente com modificação na superfície da lente e avaliação da opacidade, estimularam a realização deste estudo, o qual teve por objetivo avaliar e comparar a cápsula posterior da lente, por meio de análise histopatológica, após facoemulsificação e implante de lente intraocular (LIO), modificada com plasma de flúor ou de polietilenoglicol (PEG), em coelhos. Objetivouse também identificar as alterações histomorfológicas da cápsula posterior após colocação de LIO, analisar a imunomarcação do saco capsular, considerando os marcadores $\alpha$ actina, Ki67 e vimentina, e comparar entre os diferentes tratamentos instituídos.

\section{MATERIAL E MÉTODOS}

Foram utilizados 40 olhos de animais da espécie leporina (Oryctolagus cuniculus), da raça Norfolk, fêmeas, com idade variando entre 70 e 100 dias, e com peso entre 2 e $3 \mathrm{Kg}$. Os coelhos foram fornecidos pelo Biotério Central da UNESP, campus de Botucatu, e os procedimentos experimentais desenvolvidos seguiram as normas da Association for Research in Vision and Ophthalmology (ARVO) e foram aprovados na comissão de ética da FMVZ UNESP - Botucatu (protocolo $n^{\circ}$ 041/2012).

Os animais foram previamente submetidos aos exames clínicos e oftalmológicos de rotina a fim de se descartar qualquer alteração ocular. Foram distribuídos, aleatoriamente, em quatro grupos experimentais, constituídos por 10 animais, designados de acordo com o tipo de tratamento efetuado: Grupo com LIOs sem tratamento (GL), Grupo com LIOs submetidos a ativação superficial por plasma de flúor (GF), Grupo com LIOs submetidos ao processo de plasma e polimerizados com polietilenoglicol (GPEG) e Grupo controle, olhos submetidos apenas ao procedimento cirúrgico de facoemulsificação, sem implante LIO (GC). Então, foram anestesiados utilizando-se como medicação préanestésica: quetamina $(20 \mathrm{mg} / \mathrm{kg})$ associada à xilazina $(1 \mathrm{mg} / \mathrm{kg})$ e morfina $(0,5 \mathrm{mg} / \mathrm{kg})$, todos por via intramuscular (IM). A anestesia tópica ocular foi realizada utilizando-se colírio à base de proximetacaína $0,5 \%$. Todos os animais foram submetidos à técnica de facoemulsificação bimanual e implantação ou não de lente intraocular dobrável acrílica (Ioflex Mediphacos hidrofílica), dependendo do seu grupo experimental. No pós-cirúrgico imediato, o meloxicam $(0,2 \mathrm{mg} / \mathrm{kg} / \mathrm{IM})$ foi administrado, bem como durante três dias pós-operatórios $(0,1 \mathrm{mg} / \mathrm{kg})$, a cada 24 horas, por via subcutânea. Como profilaxia tópica antimicrobiana e antiinflamatória, foram administrados colírio de tobramicina $0,3 \%$ e colírio de acetato de prednisolona $1 \%$, e, para controle da hipertensão ocular pós-operatória, foi instilado colírio de brimonidina $0,03 \%$ a cada 6 horas durante 10 dias. Após o procedimento cirúrgico, os animais foram identificados e mantidos em gaiolas individuais com água potável e ração comercial ad libitum. Os animais foram submetidos a exames clínicos e oftalmológicos rotineiramente. 
Ao final de 12 semanas após o procedimento cirúrgico de facoemulsificação (M12), quatro animais de cada grupo foram eutanasiados, utilizando-se anestesia com acepromazina $(1,5 \mathrm{mg} / \mathrm{Kg})$ associada a quetamina $(20 \mathrm{mg} / \mathrm{Kg})$, ambas por via IM, seguida pela administração intravenosa de tiopental $(25 \mathrm{mg} / \mathrm{kg})$ e de cloreto de potássio $19,1 \%(2 \mathrm{ml} / \mathrm{Kg})$; em seguida, todos foram submetidos a enucleação do olho operado. Os demais coelhos de cada grupo $(n=6)$ foram mantidos durante 24 semanas de pós-operatório $(\mathrm{M}=24)$, e então submetidos ao mesmo protocolo e procedimento anteriormente descrito.

Os bulbos oculares enucleados foram fixados em formol neutro tamponado $10 \%$ durante 48 horas; a seguir, as cápsulas da lente foram removidas. As cápsulas formam seccionadas longitudinalmente, obtendo-se duas metades do saco capsular; as LIO, quando presentes, foram juntamente incisadas, sendo retiradas posteriormente. Os sacos capsulares foram macroscopicamente avaliados quanto ao seu aspecto, então incluídos em álcool $70 \%$ durante 12 horas e submetidos ao processo histológico para avaliação histomorfométrica e avaliação imuno-histoquímica.

$\mathrm{Na}$ coloração HE, foram analisadas as cápsulas anterior e posterior, utilizando-se microscópio Leica DMLD ${ }^{\circ}$ com software de captura de imagens Leica Qwin Standard Versão 3.5.0. Nas imagens capturadas, foram mensuradas a distância entre cápsula anterior e posterior $(\mu \mathrm{m})$, espessura das cápsulas anterior e posterior e avaliada a morfologia celular presente nas mesmas. Utilizaram-se escores de classificação para celularidade, ou seja, células epiteliais da lente observadas na cápsula posterior e o enrugamento na cápsula posterior, sendo (0) ausente, (1) leve, (2) moderada e (3) grave.

As amostras dos sacos capsulares, depois de coladas em lâminas silanizadas e carregadas positivamente, foram submetidas à desparafinização e hidratação. Foram realizados os bloqueios da peroxidase endógena $\left(\mathrm{H}_{2} \mathrm{O}_{2}\right.$ a $3 \%$ e proteína inespecífica com $1 \%$ de BSA para incubação overnight com os anticorpos Ki67 (SP6 - Abcam $\AA / 1: 100)$; alfa-actina (CGA7 Santa Cruz ${ }^{\circledR} / 1: 50$ ) e para vimentina (V9/Ivintrogen $® / 1: 100)$. Após a incubação com o anticorpo primário, as amostras foram processadas com o kit REVEAL Sistema de Detecção Livre de Biotina-Spring Biogen para revelação para peroxidase e contracorado com hematoxilina. As amostras também foram analisadas no microscópio Leica DMLD® acoplado com o software de captura de imagens, seguida da análise quantitativa no programa AVSoft BioView 4®.

$\mathrm{Na}$ análise estatística, foi utilizada a técnica da análise de variância não paramétrica para $o$ modelo com os dois fatores (grupos e momentos de avaliação), complementou-se a técnica de análise com o teste de comparações múltiplas de Dunn (Zar, 2009), considerando o nível de 5\% de significância.

\section{RESULTADOS E DISCUSSÃO}

$\mathrm{Na}$ análise histomorfométrica, observou-se a presença de uma membrana basal mais espessa na porção anterior e mais fina na porção posterior, sendo estas as cápsulas anterior e posterior; adicionalmente, verificaram-se células epiteliais cuboides na cápsula anterior, na região equatorial e na cápsula posterior (Fig. 1a) em todos os grupos avaliados. Avaliações similares às encontradas na literatura, pois se observa em uma lente normal, uma cápsula mais espessa no polo anterior e progressivamente mais fina no polo posterior (Wilcock, 2007). Cápsulas anteriores e posteriores caninas, depois de cultivadas em meios contendo soro e meios livres de soro, foram avaliadas quanto à proliferação das CELs, e constatou-se que as células presentes nas cápsulas apresentavam a aparência cuboide (Davidson et al., 2000). Semelhantemente ao observado neste estudo, uma vez que as células encontradas nas cápsulas posteriores apresentavam morfologia cuboide, sendo presumidamente células epiteliais proliferadas.

Quatro coelhos não apresentaram celularidade na cápsula posterior no $\mathrm{M} 12 \quad(\mathrm{GL}=1, \mathrm{GF}=1$ e $\mathrm{GPEG}=2)$ e cinco, no $\mathrm{M} 24(\mathrm{GL}=3 ; \mathrm{GF}=2)$, como é constatado na Figura 1b. Esses coelhos possuíam o implante LIO, e tal fato pode ser explicado pela associação do tratamento instituído nas LIOs, mas também pela própria presença da LIO, uma vez que ela pode exercer um efeito barreira, impedindo a exposição das CELs ao humor aquoso que é rico em fator transformador $\beta$, responsável pela transição 
epitelial-mesenquimal das CELs (Shirai et al., 2004; Wedje et al., 2004). Salienta-se ainda que esse efeito barreira impede o acesso de nutrientes e fatores de crescimento, resultando na regressão e atrofia das CELs que migraram para cápsula posterior (Hollick et al., 1998).

CELs migraram e foram observadas nas cápsulas posteriores de coelhos submetidos a facoemulsificação e colocação de LIO, avaliados até sete semanas de pós-operatório, assim como foi observada ausência de CELs na cápsula posterior de um coelho avaliado (Nishi et al., 2007). No presente estudo, observou-se a migração de células epiteliais nas cápsulas posteriores de coelhos avaliados em 12 e 24 semanas de pós-operatório.

Um padrão de desenvolvimento da região cortical, ou seja, o recrescimento das fibras lenticulares, foi observado em todas as lentes deste estudo, não havendo diferenças entre os grupos avaliados. Alguns autores descrevem a regeneração das fibras lenticulares como parte da patogênese da OCP (Awasthi et al., 2009; Raj et al., 2009). A presença do recrescimento foi constatada na coloração $\mathrm{HE}$, e foi possível evidenciar a "regeneração" das fibras lenticulares em todas as amostras dos diferentes grupos avaliados neste estudo; isso se deve provavelmente a uma particularidade dos coelhos, que apresentam um padrão de proliferação e regeneração considerável. Gwon et al. (1993) observaram, após a extração da lente de coelhos adultos, o desenvolvimento de grande recrescimento do córtex lenticular. Esse recrescimento foi observado em três semanas de pós-operatório no grupo controle, e em seis semanas no grupo tratado com Concanavalina A (Con-A). Além disso, após sete meses de pósoperatório, o preenchimento máximo do saco capsular da lente foi observado (Gwon et al., 1993). No presente estudo, observou-se esse recrescimento completo em 12 semanas de pósoperatório em todos os grupos avaliados.

A celularidade na cápsula posterior não apresentou diferença estatística entre os diferentes grupos de tratamento ou momentos de avaliação. No entanto, considerando os escores de mediana e valores mínimos e máximos, observaram-se escores menores para celularidade nos GL e GPEG, nos dois momentos de avaliação, quando comparados aos demais grupos. Em lentes caninas com LIO, cultivadas em meio contendo soro, observou-se a proliferação celular, no entanto a regressão de densidade celular, presumivelmente por morte celular, também foi observada (Davidson et al., 2000).

Saxby et al. (1998), analisando culturas de células epiteliais de cápsulas anteriores e posteriores da lente bovina e humana, por 12 semanas, descreveram o crescimento de células epiteliais na cápsula posterior em diferentes meios, com ou sem soro fetal, anteriormente livre desse epitélio. Nas duas espécies, a presença de multicamadas foi sempre maior com o meio contendo soro, atingindo o máximo de cinco e 12 camadas de células, respectivamente, nas cápsulas humana e bovina (Saxby et al., 1998). Neste estudo, foram observadas multicamadas na cápsula posterior, sendo em média três camadas de células epiteliais em cápsulas posteriores do GC. Os GPEG, GF e GL apresentaram em média uma camada de células epiteliais na cápsula posterior.

$\mathrm{Na}$ avaliação da espessura da cápsula posterior (Tab. 1), no M12, os GL e GPEG apresentaram diferença significativa $(\mathrm{p}<0,05)$ em suas espessuras quando comparados ao GC. Em valores numéricos, o GPEG apresentou a menor espessura da cápsula posterior da lente no M12; e ainda o GPEG apresentou uma elevação significativa em sua espessura nos diferentes momentos de avaliação. No M24, não foram observadas diferenças significativas entre os grupos, e o menor valor numérico observado foi no GL.

Devido a uma série de avanços, a ocorrência de OCP diminuiu ou pelo menos o seu início foi adiado (Sinha et al., 2013); e com exceção da menor espessura verificada nos GL e GPEG, nos demais tratamentos não foram observados retardo ou diminuição das alterações relacionadas a OCP e descritas por Sinha et al. (2013). Diferentemente de Werner et al. (2004) e Awasthi et al. (2009), que sugerem que as diversas técnicas existentes, com diferentes graus de sucesso, tendem a diminuir a OCP, neste estudo, no M24, a utilização do tratamento à base de plasma de polietilenoglicol e flúor não promoveu a redução ou diminuição da OCP. 
Coelhos que receberam LIO tratada com plasma de flúor apresentaram OCP maior no M12 quando comparadas aos coelhos que receberam LIO tratada com PEG (Sereno, 2012). Além disso, não foram observadas evidências na redução da OCP, na fase inicial, nos coelhos com
LIO tratada com plasma de flúor em relação aos demais tratamentos (Sereno, 2012). No presente estudo, de modo similar, os maiores valores de espessura também foram observados no GF, quando comparados aos do GEPG e GL, apesar de não significativo.

Tabela 1. Espessura média da cápsula posterior de coelhos (espessura $\mathrm{CP}$ ) em $\mu \mathrm{m}$, segundo grupo $\mathrm{e}$ momentos de avaliação em semanas

\begin{tabular}{|c|c|c|c|}
\hline & \multirow{2}{*}{ Grupo } & \multicolumn{2}{|c|}{ Momento de Avaliação } \\
\hline & & M12 & M24 \\
\hline \multirow{4}{*}{$\begin{array}{c}\text { Espessura da cápsula } \\
\text { posterior }\end{array}$} & GL & $6,25(3,99 ; 10,32) *$ & $6,96(5,77 ; 17,89)$ \\
\hline & GF & $7,91(6,90 ; 9,58)$ & $8,15(6,33 ; 11,08)$ \\
\hline & GPEG & $5,80(5,20 ; 6,47) \infty+$ & $11,74(7,71 ; 19,31)+$ \\
\hline & $\mathrm{GC}$ & $11,44(8,27 ; 21,06) * \infty$ & $8,02(7,04 ; 13,45)$ \\
\hline
\end{tabular}

*, $\infty$ : comparação entre grupos, fixado o momento, sendo $\mathrm{P}<0,05$. +: comparação entre os momentos, fixado o grupo, sendo $\mathrm{P}<0,05$. GL: grupo lente; GF: grupo plasma de flúor; GPEG: grupo plasma de polietilenoglicol; GC: grupo controle.

O tratamento de superfícies de LIOs acrílicas a partir da polimerização por plasma de PEG reduziu inicialmente o desenvolvimento e a intensidade da OCP após facoemulsificação (Sereno, 2012). Em um estudo usando LIOs acrílicas com superfície modificada com PEG, observou-se formação de $\mathrm{OCP}$, embora significativamente menor durante a terceira e sexta semanas no grupo LIO tratada com PEG (Lee et al., 2007). Neste estudo histológico, pode-se notar o menor valor da espessura no GPEG, e significativo em relação ao GC, indicando uma possível ação inibitória na fase inicial. Dessa forma, os dados obtidos no presente estudo corroboram os de Lee et al. (2007) e Sereno (2012), os quais concluíram que a modificação da superfície das LIOs acrílicas com PEG pode reduzir a formação de OCP durante a fase precoce. Novos estudos ainda são necessários para avaliar a eficácia e as complicações do uso de fármacos de liberação lenta, como ciclosporina A, inibidores de metaloproteinases (Liu et al., 2013); a partir do presente estudo, pode-se sugerir que a utilização do PEG, com microesferas de liberação lenta, poderia trazer benefícios no retardo do desenvolvimento da OCP, uma vez que ele se mostra eficaz no controle da OCP numa fase precoce. No entanto, considerando a OCP, nas avaliações finais, não foram encontradas diferenças significativas (Lee et al., 2007; Sereno, 2012). Esse mesmo comportamento foi verificado na fase mais tardia, ou seja, sem diferenças entre os grupos avaliados, possivelmente pela ausência de ação inibitória do PEG, indicando que o uso da tecnologia de plasma não impediu em longo prazo a proliferação celular (Sereno, 2012). Salienta-se que o coelho apresenta uma taxa de proliferação muito intensa, não somente no bulbo ocular, mas em diversos órgãos, e que a avaliação de seis a oito semanas de pós-operatório corresponderia a aproximadamente dois anos em humanos (Werner et al., 2004). Neste experimento, o período final de 24 semanas corresponderia, portanto, a um prazo maior em anos e o efeito do plasma de PEG ou demais tratamentos não foram efetivos.

$\mathrm{Na}$ avaliação clínica de coelhos submetidos a facoemulsificação e implante de LIO com superfície modificada com plasma de PEG e flúor, não foram observadas diferenças significativas entre os grupos experimentais quanto aos sinais clínicos, como blefarospasmo, fotofobia, secreção ocular, opacidade corneal, pressão intraocular, dentre outras (Sereno, 2012), indicando que os fármacos, o flúor e PEG podem seguramente ser utilizados como adjuvantes na prevenção da OCP.

$\mathrm{Na}$ avaliação da presença de enrugamento na cápsula posterior, não foram observadas diferenças estatísticas entre os grupos ou momentos de avaliação, embora a presença de enrugamento capsular posterior tenha sido 
observada em todos os grupos (Fig. 1c), diferindo apenas na intensidade. $\mathrm{O}$ GC apresentou valores de escore mais elevado nos dois momentos em relação aos demais grupos, porém não significativo. Por outro lado, o GPEG apresentou os menores escores no M12, sendo que algumas amostras não apresentaram enrugamento na cápsula posterior (escore 0 ), em relação aos demais grupos. Wong et al. (2004), após cultura de cápsulas posteriores de lentes humanas coletadas para avaliação quanto ao desenvolvimento de OCP, também observaram, no décimo dia de avaliação, a presença evidente de uma camada de células epiteliais na cápsula posterior, bem como a presença de rugas. Esses enrugamentos descritos são, portanto, similares aos observados em todos os grupos deste estudo.

Foi observada a presença de vacuolizações (Fig. 1d) no material lenticular em todos os grupos, verificando-se em maior número, por ordem decrescente, no grupo GF $(80 \%)$, GPEG $(66,66 \%)$, no GL $(50 \%)$, GC (25\%). Fernandez et al. (2004) também observaram, na análise histológica, a formação de vacuolização nos diferentes tratamentos instituídos para LIOs, ou seja, hialunorato de sódio (SHA), mitomicina C (MMC) e ácido etilenodiaminotetracético
(EDTA). Segundo Fernandez et al. (2004), essas vacuolizações representam células lenticulares mortas, necróticas. Estes descrevem ainda que o grau de vacuolização está relacionado com o grau de desorganização do crescimento das células lenticulares. E ainda que o aumento da presença de vacuolização nos olhos tratados com MMC e nos olhos tratados com EDTA é explicado pelo fato de que esses fármacos afetaram a proliferação celular de forma mais eficiente do que a água destilada, por exemplo. No presente estudo, os maiores índices de vacuolização foram notados também nos grupos de LIO tratados com polietilenoglicol e flúor, e principalmente no M12, sugerindo uma atuação dos fármacos utilizados no tratamento de superfície.

Segundo Davidson et al. (2000), cápsulas caninas cultivadas exibiam positividade para alfa-actina, e essa expressão foi vista predominantemente em associação com rugas capsulares. Neste estudo, o marcador alfa-actina foi evidenciado na cápsula posterior dos grupos experimentais (Fig. 2a), porém sem diferenças significativas entre os momentos de avaliação, nem entre os grupos avaliados.

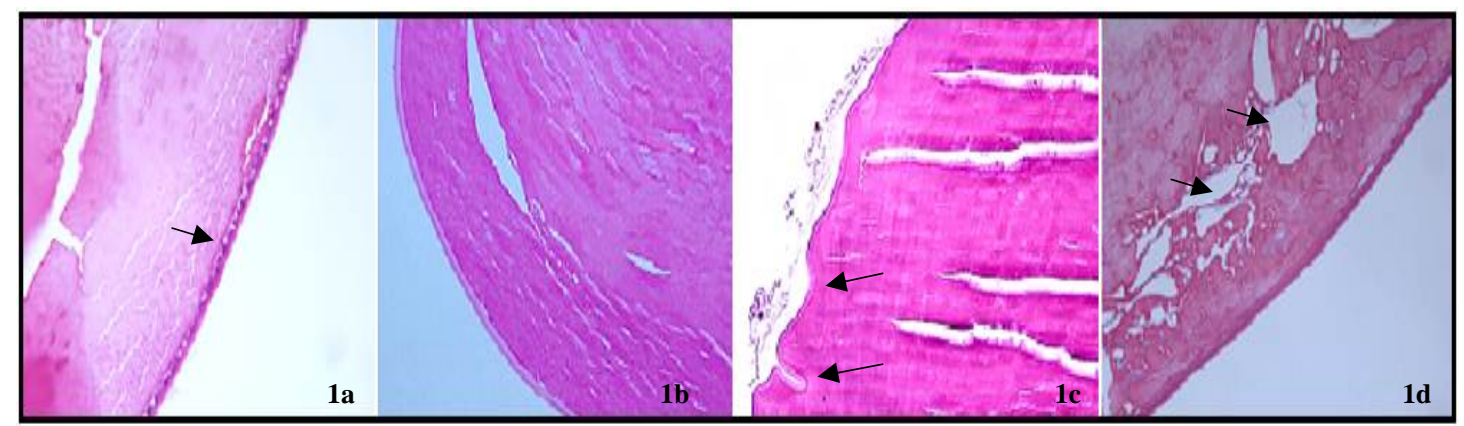

Figura 1. Fotomicrografia de corte histológico da cápsula posterior, HE, 40X. 1a: observar a presença de celularidade (seta) do coelho do grupo controle no M24; 1b: cápsula posterior livre de celularidade (seta) do coelho do grupo polietilenoglicol no M12; 1c: notar o enrugamento grave (seta) do coelho do grupo controle no M24; 1d: observar a presença de vacuolização (setas) do coelho do grupo plasma de flúor.

Paralelamente ao enrugamento na cápsula posterior, observou-se que a maioria das cápsulas posteriores positivas para a imunomarcação de alfa-actina também apresentavam enrugamento nos cortes histológicos, corroborando o descrito por Davidson et al. (2000) e Wormstone et al. (2009).
Células epiteliais da lente de cápsulas posteriores humana e bovina foram positivas para alfa-actina nas cápsulas cultivadas (Saxby et al., 1998). Além disso, o alfa-actina é considerado um marcador importante para células contráteis, e tal observação pode explicar a contração e enrugamento da cápsula posterior (Nagamoto et al., 1997; Saxby et al., 1998). As CELs A são positivas a alfa-actina e promovem a contração e 
o enrugamento da cápsula posterior (Wormstone et al., 2009). O enrugamento descrito também foi observado neste estudo, independentemente do grupo experimental, corroborando os achados desses autores.

O anticorpo Ki67, importante marcador de proliferação celular, é expresso em todas as fases do ciclo celular G1, S, G2, no entanto células quiescentes ou na fase G0 não o expressam (Hall e Levison, 1990). A imunomarcação celular para o marcador Ki67 na cápsula posterior foi evidenciada em todos os grupos avaliados (Fig. $2 b$ ), porém sem diferenças significativas entre os grupos experimentais. Apenas no GL verificouse uma redução significativa no M12 em relação ao M24, provavelmente devido à maior evidência numérica de proliferação celular no M12, nesse grupo experimental (Tab. 2). Foram observadas células epiteliais na cápsula posterior nos cortes histológicos, embora algumas amostras tenham sido negativas para esse marcador, indicando que essas células não estavam em proliferação, corroborando o descrito por Nishi et al. (2007), que constataram que células epiteliais da lente estavam presentes na cápsula posterior, embora a grande maioria dos núcleos tenham sido negativos para Ki67, concluindo que essas células estavam na fase G0 do ciclo celular, indicando ausência proliferativa.

No M12, os grupos com LIO tratadas apresentaram menores quantidades de células positivas para o anticorpo $\mathrm{Ki67}$ quando comparados com o grupo LIO sem tratamento, mostrando eficácia do tratamento no controle da proliferação celular.

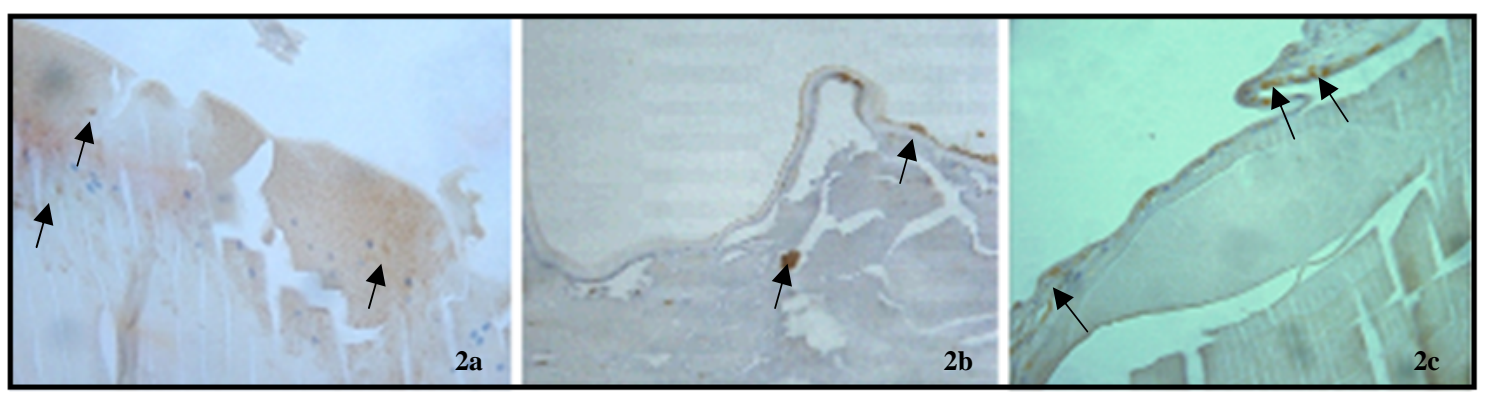

Figura 2a: Imunomarcação para alfa-actina na cápsula posterior do coelho do grupo polietilenoglicol (setas); 2b: Imunomarcação para Ki67 na cápsula posterior do coelho do grupo polietilenoglicol (setas); 2c: Imunomarcação para vimentina na cápsula posterior do coelho do grupo controle (setas). $2 \mathrm{a}-2 \mathrm{c}$ : aumento 40X.

A vimentina foi positiva em todos os grupos (Fig. 2c), e à similitude dos outros marcadores, não foram observadas diferenças significativas entre os grupos e momentos. Shirai et al. (2004) analisaram uma cápsula posterior humana, após procedimento de capsulotomia posterior, e
Davidson et al. (2000) avaliaram amostras de lentes caninas cultivadas; ambos observaram, na análise imuno-histoquímica, células positivas para os marcadores vimentina e alfa-actina, dados semelhantes aos encontrados neste estudo.

Tabela 2. Quantidade de células imunomarcadas com Ki67 na cápsula posterior, segundo grupo e momentos de avaliação em semanas

\begin{tabular}{|c|c|c|c|}
\hline \multirow{2}{*}{ Variável } & \multirow{2}{*}{ Grupo } & \multicolumn{2}{|c|}{ Momento de Avaliação } \\
\hline & & M12 & M24 \\
\hline \multirow{4}{*}{ Quantidade de células (Ki67) } & GL & $2,5(2,0 ; 3,0) *$ & $0,0(0,0 ; 2,0) *$ \\
\hline & GF & $0,0(0,0 ; 1,0)$ & $0,0(0,0 ; 7,0)$ \\
\hline & GPEG & $0,0(0,0 ; 3,0)$ & $0,0(0,0 ; 1,0)$ \\
\hline & $\mathrm{GC}$ & $1,0(0,0 ; 4,0)$ & $0,0(0,0 ; 3,0)$ \\
\hline
\end{tabular}

* comparação entre momentos, fixado o grupo, sendo $\mathrm{P}<0,05$. GL: grupo lente; GF: grupo plasma de flúor; GPEG: grupo plasma de polietilenoglicol; GC: grupo controle. 
$\mathrm{Na}$ imuno-histoquímica, células epiteliais de cápsulas posteriores foram positivas para vimentina e alfa-actina, confirmando caráter miofibroblástico, sendo essas as células epiteliais da lente que sofreram transformação epiteliomesenquimal (Reys et al., 1999), o mesmo observado no presente trabalho.

A vimentina é expressa na maioria das células de origem mesenquimal, incluindo os fibroblastos (Saika et al., 1998); assim, a análise imunohistoquímica deste estudo sugere que as células positivas para a vimentina são as células epiteliais da lente remanescentes que sofreram transformação epitelio-mesenquimal, sendo, portanto, células epiteliais do tipo A (CELs-A); enquanto as células epiteliais do tipo "E (CELsE), por apresentarem uma taxa mitótica alta, dando origem a novas fibras continuamente durante a vida (Pandey et al., 2004), possivelmente tenham sido as células positivas para o marcador Ki67 de proliferação celular. A distribuição das células positivas para vimentina foi uniforme, e estava disposta ao longo da população de células, independentemente da localização na cápsula, ao passo que a expressão para o alfa-actina foi observada mais evidentemente no saco capsular e em células dentro e adjacentes às pregas e rugas na cápsula posterior (Davidson et al., 2000). Os achados do presente estudo corroboram os achados em cães, uma vez que as células positivas para vimentina distribuíam-se entre as células epiteliais presentes, tanto na cápsula posterior quanto na cápsula anterior e região equatorial, enquanto as células positivas para alfa-actina, quando presentes, localizavam-se principalmente entre as rugas da cápsula posterior.

\section{CONCLUSÕES}

Com base no estudo, conclui-se que o tratamento de lentes intraoculares com plasma de polietilenoglicol e flúor pode ser realizado como adjuvante na prevenção da opacidade de cápsula posterior, pois não causa alterações na morfologia da lente após a facoemulsificação. Os tratamentos com implante de LIO tratada com plasma de polietilenoglicol ou LIO comercial promovem menor espessura da cápsula posterior em relação à ausência do implante. Considerando as demais variáveis estudadas e avaliação até seis meses, os tratamentos da superfície da LIO à base de plasma de flúor e polietilenoglicol não reduziram o desenvolvimento das alterações histológicas associadas à opacidade de cápsula posterior. Avanços nos processos de tratamento da superfície da LIO com plasma e polimerização de polietilenoglicol devem ser estimulados, objetivando o aumento da permanência do polietilenoglicol no implante.

\section{AGRADECIMENTOS}

À CAPES E CNPq pelo apoio financeiro. Processo n³07508/2012-9.

\section{REFERÊNCIAS}

AWASTHI, N.; GUO, S.; WAGNER, B.J. Posterior capsular opacification a problem reduced but not yet eradicated. Arch. Ophthalmol., v.127, p.555-562, 2009.

BOZUKOVA, D.; PAGNOUlle, C.; PAUWGILLET, M.C. et al. Improved performances of intraocular lenses by poly(ethylene glycol) chemical coatings. Biomacromolecules, v.8, p.2379-2387, 2007.

COLTRO, L.; ALVES, R.M.V. Tratamento superficial de filmes flexíveis por plasma. Inf. CETEA, v.13, 2001.

DAVIDSON, M.G.; WORMSTONE, M.; MORGAN, D. et al. Ex vivo canine lens capsular sac explants lens capsular. Graefe's Arch. Clin. Exp. Ophthalmol., v.238, p.708-714, 2000.

FERNANDEZ, V.; FRAGOSO, M.; BILLOTTE, C. et al. Efficacy of various drugs in the prevention of posterior capsule opacification: experimental study of rabbi eyes. J. Cataract Refr. Surg., v.30, p.2598-2605, 2004.

GWON, A.; GRUBER, L.; MANTRAS, C.; CUNANAN, C. Lens regeneration in New Zealand albino rabbits after endocapsular cataract extraction. Invest. Ophth. Vis. Sci; , v.34, p.2124-2129, 1993.

HALL, P.A.; LEVISON, D.A. Review: assessment of cell proliferation in histological material. J. Clin. Pathol., v.43, p.184-192 1990.

HOLLICK, E.J.; SPALTON, D.J.; URSELL, P.G.; PANDE, M.V. Lens epithelial cell regression on the posterior capsule with different intraocular lens materials. $\mathrm{Br}$. J. Ophthalmol., v.82, p.1182-1188, 1998. 
KIM, M.K.; PARK, I.S.; PARK, H.D. et al. Effect of poly (ethylene glycol) graft polymerization of poly (methyl methacrylate) on cell adhesion. In vitro and in vivo study. $J$. Cataract Refr. Surg., v.27, p.766 - 774, 2001.

LEE, H.II; KIM, M.K.; KO, J.H. et al. The Efficacy of an Acrylic Intraocular Lens Surface Modified with Polyethylene Glycol in Posterior Capsular Opacification. J. Korean Med. Sci., v.22, p.502-507, 2007.

LIU, Y.C.; WONG, T.T.; MEHTA, J.S. Intraocular lens as a drug delivery reservoir. Curr. Opin. Ophthalmol., v.24, p.53-59, 2013.

NAGAMOTO, T.; EGUCHI, G.; BEEBE, D.C. Control of $\alpha$-smooth muscle actin expression in cultured lens cells. Invest. Ophth. Vis. Sci., v.38, suppl.43, 1997.

NISHI, O.; YAMAMOTO, N., NISHI, K.; NISHI, Y. Contact inhinition of migrating lens epithelial cells at the capsular bend created by a sharp-edged intraocular lens after cataract surgery. J. Cataract Refr. Surg., v.33, p.10651070, 2007.

PANDEY S.K.; APPLE D.J.; WERNER L. et al. Posterior capsule opacification: a review of the aetiopathogenesis, experimental and clinical studies and factors for prevention. Indian $J$. Ophthalmol., v.52, p.99-112, 2004.

RAJ, S.M.; VASAVADA, A.R.; JOHAR, K.D. et al. Post-operative capsular opacification. Nepalese J. Ophthalmol., v.1, p.43-59, 2009.

REYES, J.A.A.; VEIGA, M.A.L.; SANZ, C.M. et al. Síndrome de contracción capsular: estudo histopatológico e imunohistoquímico. Microcir. Ocular, v.2, p.75-79,1999.

SAIKA, S.; KAWASHIMA, Y.; MIYAMOTO, $\mathrm{T}$. et al. Immunolocalization of prolyl 4hydroxylase subunits, $\alpha$-smooth muscle actin, and extracellular matrix components in humans lens capsules with lens implants. Exp. Eye Res., v.66, p.283-294, 1998.

SAXBY, L.; ROSEN, E.; BOULTON, M. Lens epithelial cell proliferation, migration, and metaplasia following capsulorhexis. $\mathrm{Br} . \mathrm{J}$. Ophtalmol., v.82, p.945-952, 1998.
SERENO, M.G. Opacidade de cápsula posterior após implante de lentes intraoculares tratadas por plasma de flúor e polietilenoglicol em coelhos. 2012. 113f. Tese (Doutorado) Faculdade de Medicina Veterinária e Zootecnia, Universidade Estadual Paulista, Botucatu, SP.

SHIRAI, K.; SAIKA, S.; OKADA, Y. et al. Histology and immunohistochemistry of fibrous posterior capsule opacification in an infant. $J$. Cataract Refr. Surg., v.30, p.523-526, 2004.

SINHA, R.; SHEKHAR, H.; SHARMA, N. et al. Posterior capsular opacification: a review. Indian J. Ophtalmol., v.61, p.371-376, 2013.

WEJDE, G.; KUGELBERG, M.; ZETTERSTRÖM, C. Position of anterior capsulorhexis and posterior capsule opacification. Acta Ophthalmol. Scan., v.82, p.531-534, 2004.

WERNER, L.; LEGEAIS, J.; NAGEL, M.; RENARD, G. Evaluation of Teflon-coated intraocular lenses in an organ culture method. $J$. Biomed. Mat. Res., v.46, p.347-354, 1999.

WERNER, L.; MAMALIS, N.; PANDEY, S.K. et al. Posterior capsule opacification in rabbit eyes implanted with hydrophilic acrylic intraocular lenses with enhanced square edge. $J$. Cataract Refr. Surg., v.30, p.2403-2409, 2004.

WILCOCK, B.P. Eye and ear. In: JUBB; KENNEDY; PALMER'S. Pathology of domestic animals. 5.ed. Philadelphia: Elsevier, 2007. chap.4, p.459-543.

WONG, T.T.L.; DANIELS, J.T.; CROWSTON, J.G.; KHAW, P.T. MMP inhibition prevents human lens epithelial cell migration and contraction of the lens capsule. $\mathrm{Br} . \mathrm{J}$. Ophtalmol., v.88, p.868-872, 2004.

WORMSTONE, I. M.; WANG, L.; LIU, C.S.C. Review Posterior capsule opacification. Exp. Eye Res., v.88, p.257-269, 2009.

ZAR, J.H. Biostatistical analysis. 5.ed. New Jersey: Prentice-Hall. 2009. 994p. 